\title{
Peripheral T-Cell Lymphoma, Not Otherwise Specified
}

National Cancer Institute

\section{Source}

National Cancer Institute. Peripheral T-Cell Lymphoma, Not Otherwise Specified. NCI

Thesaurus. Code C4340.

A heterogenous category of nodal and extranodal mature T-cell lymphomas that do not correspond to any of the specifically defined entities of mature T-cell lymphoma in the 2017 WHO classification. Excluded from this category are tumors with a T follicular helper (TFH) cell phenotype. Variants include lymphoepithelioid lymphoma (Lennert lymphoma) and primary EBV-positive nodal T-cell or NK-cell lymphoma. The follicular variant included in the peripheral T-cell lymphomas, not otherwise specified, in the 2008 edition of the WHO classification has been moved to the category of angioimmunoblastic T-cell lymphoma and other nodal lymphomas of T follicular helper cell origin in the 2017 WHO update. The same is true for a proportion of cases previously designated as the T-zone variant, because they usually have a TFH-cell phenotype.

(WHO 2017) 